\title{
Household storage of medicines and self-medication practices in south-east Islamic Republic of Iran
}

\author{
B. Foroutan ${ }^{1}$ and R. Foroutan ${ }^{2}$
}

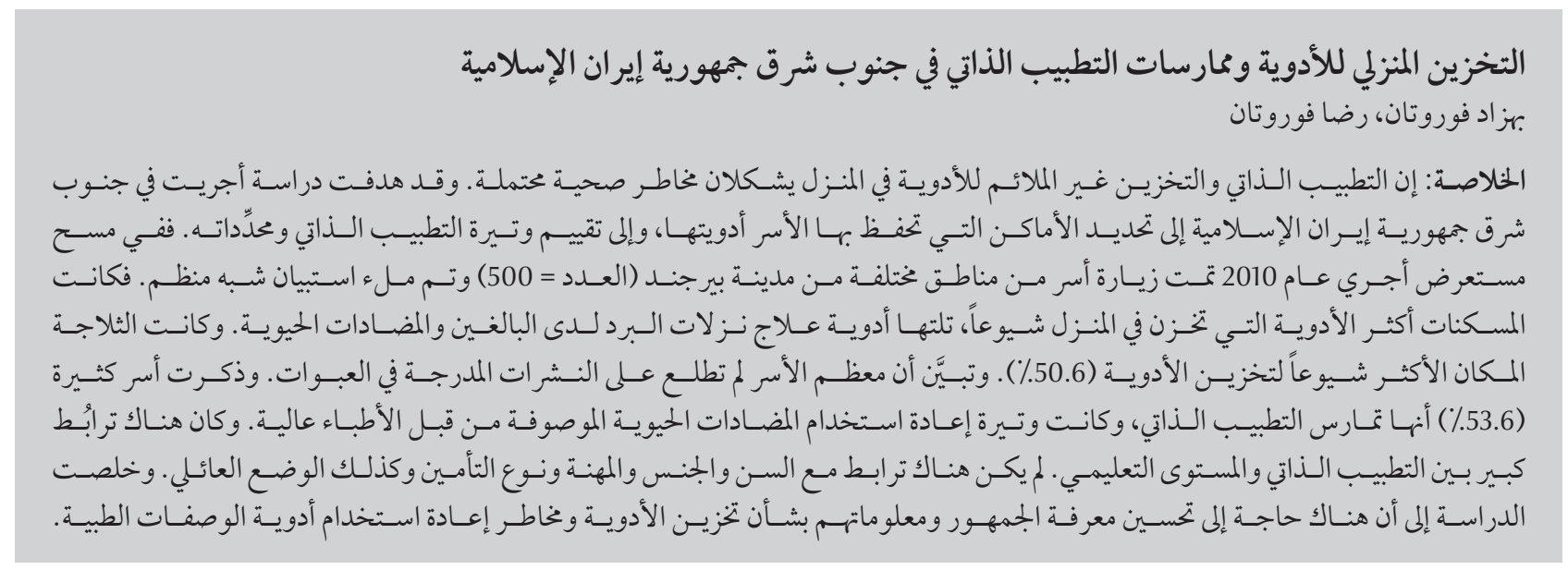

ABSTRACT Self-medication and inappropriate storage of medicines at home are potential health risks. This crosssectional study in south-east Islamic Republic of Iran in 2010 aimed to determine where householders kept their medicines and to assess the frequency and determinants of self-medication. Householders from different parts of Birjand city $(n=500)$ were visited and completed a semi-structured questionnaire. Analgesics were the most common medicines stored at home, followed by adult cold remedies and antibiotics. The refrigerator was the most common place for storing medicines (50.6\%). Most householders did not consult the package inserts. Many householders (53.6\%) reported that they practised self-medication, and the frequency of reuse of physicianprescribed antibiotics was high. There was a significant association between self-medication and educational level but not with age, sex, martial status, occupation and type of insurance. Better public knowledge and information about storage and risks of reuse of prescription medications is needed.

Conservation de médicaments à domicile et pratiques d'automédication dans le sud-est de la République islamique d'Iran

RÉSUMÉ L'automédication et la conservation inappropriée de médicaments à domicile représentent des risques potentiels pour la santé. La présente enquête transversale réalisée en 2010 dans le sud-est de la République islamique d'Iran visait à déterminer où les ménages conservaient leurs médicaments et à évaluer la fréquence de l'automédication et ses déterminants. Des ménages dans différents quartiers de la ville de Birjand $(n=500)$ ont fait l'objet d'une visite et ont rempli un questionnaire semi-structuré. Les analgésiques étaient les médicaments les plus couramment conservés à domicile, suivis par les médicaments contre le rhume chez l'adulte et les antibiotiques. Le réfrigérateur était l'endroit le plus fréquent pour la conservation des médicaments (50,6\%). La plupart des ménages ne consultaient pas les notices des médicaments. De nombreux ménages (53,6 \%) ont affirmé qu'ils pratiquaient l'automédication, et la fréquence de réutilisation des antibiotiques prescrits par un médecin était élevée. Il existait une forte association entre l'automédication et le niveau d'études, contrairement à l'âge, au sexe, à la situation matrimoniale, au métier et au type d'assurance. La population a besoin d'accroître ses connaissances et son niveau d'information sur la conservation des médicaments et sur les risques liés à la réutilisation des médicaments prescrits.

'Department of Pharmacology, School ofMedicine, Shahroud University of Medical Sciences, Shahroud, Islamic Republic of Iran (Correspondence to B. Foroutan: behzad_foroutan@hotmail.com). ${ }^{2}$ School of Medicine, Shiraz University of Medical Sciences, Shiraz, Islamic Republic of Iran.

Received: 10/06/13; accepted: 16/04/14 


\section{Introduction}

Self-medication is a global concern, in both developed and developing countries (1-9) including those of the Middle East (10-12). It has been estimated that about $60-80 \%$ of health problems are treated by self-medication (13). This is a practice in which individuals utilize any types and dosages of medication for treating themselves, without professional supervision, to control an illness or an abnormal condition $(14,15)$. Based on the official figures, annual sales of non-prescription products in the United States of America exceed US\$ 31 billion, although these sales represent less than $20 \%$ of total spending on prescription pharmaceuticals (16). Concerns about self-medication include sharing prescription medicines with other members of the family, using leftovers from previous prescriptions or disrespecting the medical prescription by prolonging or interrupting the dosage and the administration period prescribed (1).

Inappropriate storage and use of medicines at home could have a direct influence on public health, the environment and the health-care services and it increases the risk of self-medication (17). Previous studies have identified a link between medicine storage and self-medication practices (18). This includes medications stored intentionally while they remain in use or medications that are incompletely used. Storing medicines at home might increase the risk of self-medication, and some authors have reported a high frequency of exchange of self-medication between family members (11). Self-medication is influenced by many factors, such as local legislation and accessibility of medicines; advertisements by pharmaceutical companies; individuals' level of education, number of family members and income; and local societal and cultural norms. One of the main reasons for self-medication is often the financial burden of consulting a doctor. In economically deprived communities, most episodes of illnesses are treated by self-medication (19), which provides a low-cost alternative for people who cannot afford the high cost of clinical services and also as many medicines in developing countries are dispensed over-the-counter.

The present study in a city in the south-east of the Islamic Republic of Iran aimed to find out where medicines were kept at home, to investigate the frequency and determinants of selfmedication among family members and to explore whether or not the medication package inserts were used. The study would inform strategies such as educational programmes aiming to promote public knowledge about medicines. These strategies would help householders to pay more attention to storing medicines at home and raise awareness of self-medication practices.

\section{Methods}

\section{Sampling}

The study was conducted in March 2010 in the city of Birjand, south-east of Islamic Republic of Iran. A sample of 500 householders were recruited by stratifying the local regions of the city (north, south, east, west and central) into different sections to cover families of different socioeconomic status. Householders from each section were selected through a systematic, random sampling technique to cover all parts of the city. Local authorities were contacted to obtain formal permission to conduct the study and householders were informed in advance about the study to ensure their agreement to participate in the study. Selected households were visited and the data collection supervisors explained the objectives of the study. Heads of households were asked to consent for their home to be included in the study and for them to participate in filling the questionnaires. They were told that their names and those of their families would not be recorded. Each household was given a code and considered as a unit. When a householder was not willing to participate the next household in the sampling frame was taken until the sample size was reached $(n=500)$.

\section{Data collection}

The survey was conducted by 2 students who were trained by the researcher by conducting several household visits in the presence of the researcher before the actual start of the study.

Householders completed a pretested, researcher-designed questionnaire which collected data about their demographic characteristics (age, sex, marital status, education, occupation and insurance coverage/organization) and asked about use of medicines at home. They were asked: whether they kept medicines in the house; whether they read the package inserts; where they kept the medicines (refrigerator, kitchen cabinet, bedroom, bathroom, elsewhere); whether they stored prescription medicines for re-use; what kinds of medicines were reused (pain, fever, antibiotics, cold cures, herbal medicines); whether they returned unused medicine to the pharmacy; whether they knew about self-medication; what formulations of medicines they kept (tablets, drops, syrup capsules injections suppositories, creams/ointment); how many times in the past 3 months they self-medicated without consulting the doctor (once, twice, three times, more than three times); and whether they paid attention to the expiry date of the medicines. The questionnaire contained both open-ended questions and questions with a list of possible answers. We defined leftover medicines as medications prescribed by the doctor over the previous 3 months and kept by the householder. Medicine names, strength, dosage form, expiry date and quantity were recorded. We did not record householders' income because most of participants were employed 
within a similar range of annual income and there were few unemployed householders. Educational status was analysed in 2 categories: no formal education or primary school only; and secondary school or higher.

\section{Data analysis}

The data were reviewed, organized, tabulated and analysed using Microsoft Excel, 2010 version. Descriptive analysis was conducted by calculating means and standard deviation (SD) and proportions for continuous and discrete data respectively. The chi-squared and t-tests were used to analyse statistical significance. The cut-off for statistical significance was $P<0.05$.

\section{Results}

A total of 500 householders completed the questionnaires: 231 (46.2\%) females and 269 (53.8\%) males. Table 1 shows their demographic characteristics. Of the householders, $62.8 \%$ had completed secondary school or higher levels and $37.2 \%$ had no schooling or only primary school level. Most of the participants $(73.6 \%)$ were married and living with their families, while $26.4 \%$ were single. One-third (34.4\%) of householders had no insurance coverage/organization to support and cover medication costs and 5.0\% of participants were unemployed.

All the households reported that they kept medicines at home. Table 2 shows the places where medicines were kept at home. The most common place was the refrigerator $(50.6 \%)$ or a kitchen cupboard (42.6\%); the remainder kept medicines in the bedroom. None of the households kept medicines in the bathroom. Only 6.8\% of the householders said that they had read the instructions in the manufacturers' patient information leaflets (package inserts) and $93.2 \%$ did not (some participants admitted that they threw away the leaflets).
Overall,268 (53.6\%) householders reported that they practised self-medication for self-diagnosed disorders or symptoms. Table 2 also shows the most commonly reported therapeutic categories used for self-medication. Analgesics (e.g. non-steroidal antiinflammatories, paracetamol and its related compounds or combinations such as paracetamol plus codeine) were the main therapeutic group, used by $59.6 \%$ of respondents for self-medication. The number of times within the last 3 months that householders had self-medicated themselves and their families with analgesics were as follows: 1 time (19.4\%); 2 times (22.4\%); 3 times (16.8\%) and $\geq 3$ times (41.4\%). Adult cold remedies were used for selfmedication by $11.6 \%$ of respondents, antibiotics (left-overs from doctors' prescriptions) by $9.8 \%$, herbal remedies by $9.2 \%$ and corticosteroids by $7.0 \%$ (Table 2 ). In answer to the question related to reuse of antibiotics prescribed by the doctor, one-third reported that they reused them. Of those who reused antibiotics, $70.7 \%$ reported that they did not know this type of use was self-medication. The results also showed that tablets were the most commonly used formulation for self-medication (35.6\%), followed by capsules $(24.4 \%)$; syrup $(21.4 \%)$, ointments (10.8\%); ampoules (4.0\%) and suppositories (3.8\%).

Table 3 shows self-medication practices by age, sex, occupation and insurance coverage/organization name. There was a significant association between self-medication practices and educational level ( $P=$ 0.007). Respondents with secondary/ higher education were less likely to use self-medication than those who had none/primary education only. There was no significant association between self-medication and age, sex, marital status, occupation or type of insurance.

\begin{tabular}{lcc}
\hline Table 1 Demographic characteristics of participants $(\boldsymbol{n}=\mathbf{5 0 0})$ & \\
Variable & No. & \\
Sex & 231 & 46.2 \\
$\quad$ Female & 269 & 53.8 \\
$\quad$ Male & $29.4(1.32)$ \\
Mean (SD) age (years) & 368 & \\
Marital status & 132 & 73.6 \\
$\quad$ Married & & 26.4 \\
$\quad$ Single & 260 & \\
Occupation & 101 & 52.0 \\
$\quad$ Government employee & 60 & 20.2 \\
$\quad$ NGO employee & 54 & 12.0 \\
Housewife & 25 & 10.8 \\
$\quad$ Retired & & 5.0 \\
$\quad$ Unemployed & 196 & 39.2 \\
Insurance cover/organization & 122 & 24.4 \\
$\quad$ Social security insurance & 10 & 2.0 \\
Iran health insurance & 172 & 34.4 \\
Other health insurance & & \\
No insurance & 314 & \\
Education & 186 & \\
Secondary school/higher & & \\
$\quad$ None/primary school only & & \\
\hline
\end{tabular}

$N G O=$ nongovernmental organization . 


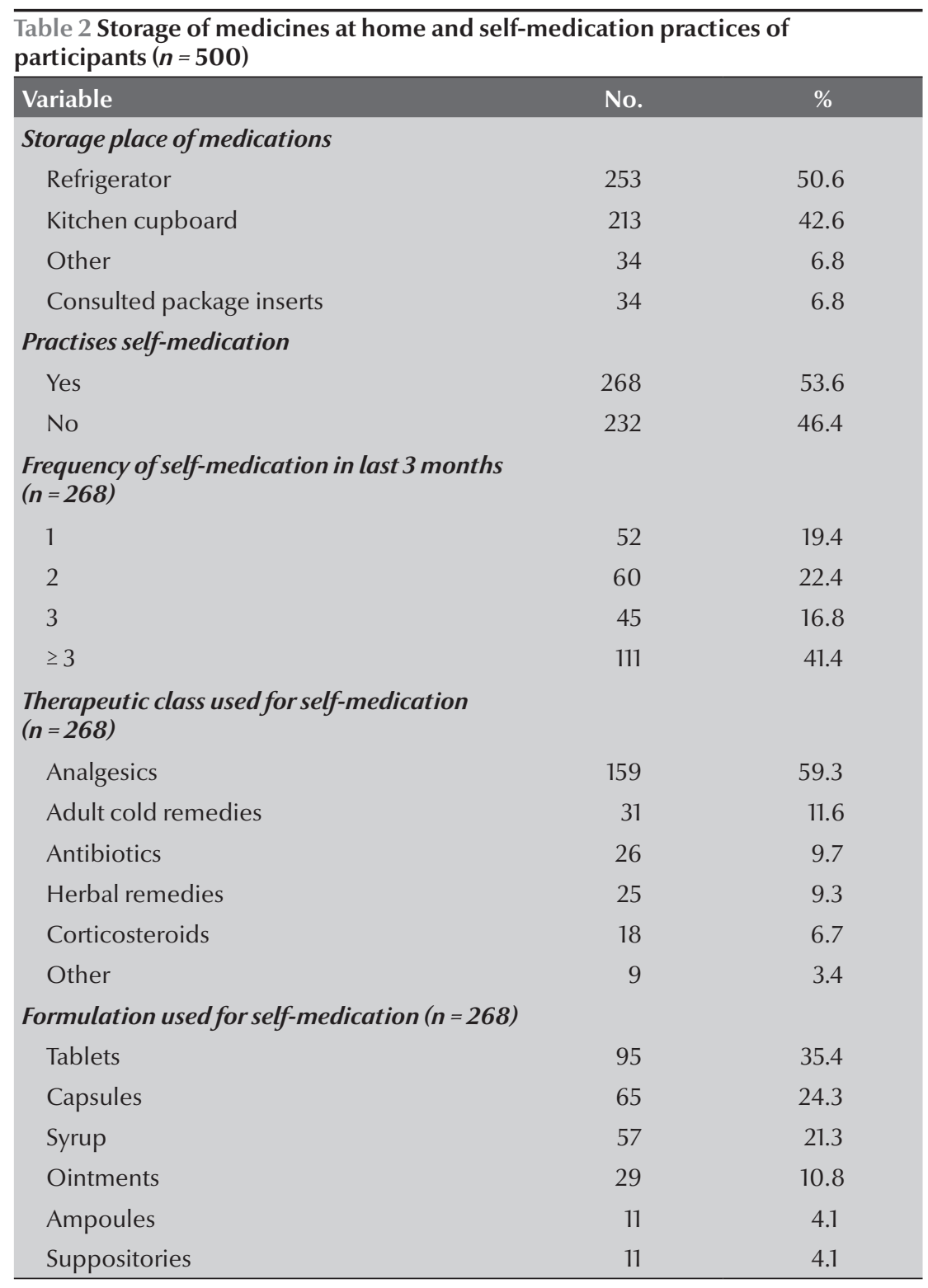

\section{Discussion}

Our study revealed that nearly half of households stored medicines in the refrigerator, whether this was the correct place or not. The correct place for storage depends on the medicine; for example, after preparation of antibiotic suspensions they must be kept cool but not frozen, whereas adult cold remedies should be kept at room temperature in a kitchen or bedroom cupboard. The kitchen cupboard was the second most common storage place. This finding contrasts with that of other countries. In a study in Qatar, for example, most medicines were kept in the bedroom earlier than the expiry date, or even become toxic, especially antibiotics. Places such as cabinets and kitchen cupboards might be suitable although humidity should also be considered.

Pharmaceutical companies in the Islamic Republic of Iran are required to include a leaflet with medication packages which briefly explains about the drug, its indications and side-effects. This covers most outpatient prescription and some non-prescription medicines and medical supplies. Only 6.8\% of householders said that they had read the package inserts.

Even if medicines are stored correctly, it does not mean that these medicines would be suitable for a family member to start self-medication and reuse them. None of the householders in our study reported routinely returned unwanted medications to a pharmacy for proper disposal. Furthermore, a high prevalence of self-medication was noted among householders (53.6\%). Muras et al. reported that antibiotic self-medication for respiratory tract infection was common in Poland (22).

Previous studies have documented the link between medicine storage places at home and frequency of self-medication $(23,24)$. Medicines prescribed for one symptom/disease may be used both as self-medication for (repeated) episodes of the same symptom/disease or for a member of the family with the same symptom/disease but not by consultation with a physician. Finding unused prescription medicines in homes in the Islamic Republic of Iran is not surprising because self-medication practices are common among people of all educational levels $(11,12,25-27)$. Other research has found that the majority of householders keep unused medicines at home either to use them in the future or to give them to someone else who has similar symptoms (28). Furthermore, leftover medications may be a result of non-completion to treatment regimens (29). 


\begin{tabular}{|c|c|c|c|c|c|}
\hline \multirow[t]{3}{*}{ Variable } & \multicolumn{4}{|c|}{ Practises self-medication } & \multirow[t]{3}{*}{$\boldsymbol{P}$-value ( $\chi^{2}$ test) } \\
\hline & \multicolumn{2}{|c|}{ Yes } & \multicolumn{2}{|c|}{ No } & \\
\hline & No. & $\%$ & No. & $\%$ & \\
\hline Sex & & & & & 0.704 \\
\hline Male & 142 & 54.4 & 119 & 45.6 & \\
\hline Female & 126 & 52.7 & 113 & 47.3 & \\
\hline Age (years) & & & & & 0.832 \\
\hline $20-29$ & 58 & 50.4 & 57 & 49.6 & \\
\hline $30-39$ & 69 & 53.5 & 60 & 46.5 & \\
\hline $40-49$ & 71 & 53.8 & 61 & 46.2 & \\
\hline$\geq 50$ & 70 & 56.4 & 54 & 43.6 & \\
\hline Marital status & & & & & 0.613 \\
\hline Married & 199 & 54.1 & 169 & 45.9 & \\
\hline Single & 68 & 51.5 & 64 & 48.5 & \\
\hline Occupation & & & & & 0.544 \\
\hline Employed & 253 & 53.3 & 222 & 46.7 & \\
\hline Unemployed & 15 & 60.0 & 10 & 40.0 & \\
\hline Insurance coverage/organization & & & & & 0.728 \\
\hline Social security insurance & 103 & 52.6 & 93 & 47.4 & \\
\hline Iran health insurance & 62 & 50.8 & 60 & 49.2 & \\
\hline Other health insurance & 5 & 50.0 & 5 & 50.0 & \\
\hline None & 98 & 57.0 & 74 & 43.0 & \\
\hline Educational level & & & & & $0.007^{\mathrm{a}}$ \\
\hline Secondary/higher & 153 & 48.7 & 161 & 51.3 & \\
\hline None/primary & 115 & 61.2 & 73 & 38.8 & \\
\hline
\end{tabular}

asignificant at $P<0.05$.

There was a significant association between self-medication and educational level. Lower educated householders were more likely to selfmedicate. Self-medication provides a lower cost alternative for people who cannot afford the cost of clinical services $(30,31)$. Based on a study in India, the prevalence of self-medication was $37 \%$ in urban and $17 \%$ in rural populations (32).

The results showed that stored medicines belonged mostly to 3 categories: analgesics, adult cold remedies and antibiotics. In the Islamic Republic of Iran, analgesics are the most commonly procured over-the-counter medicines and self-medication with them is frequent. They are usually the first-line of medicines used by community members in event of illness
(33). Adult cold formulations (a combination of phenylephrine, chlorpheniramine maleate and paracetamol) are also widely consumed products in the Islamic Republic of Iran. Nearly $10 \%$ of households in the present study reported that they used antibiotics for self-medication and one-third reported that reused them. It should be noted that this study refers to antibiotics originally prescribed by the doctor and then kept and reused, as antibiotics are not sold over-the counter in the Islamic Republic of Iran. This may be in order to save money because antibiotics are expensive to buy. In Saudi Arabian households Abou-Auda found that respiratory medicines, followed closely by central nervous system (CNS) agents and antibiotics, were the most common reused medicines $(16.8 \%, 16.4 \%$ and
$14.3 \%$ respectively) (34). In contrast, a British study revealed that among medicines returned to pharmacies, $28.0 \%$ were cardiovascular medicines, $19.1 \%$ were CNS agents, $14.8 \%$ were respiratory agents, $11.4 \%$ were gastrointestinal agents and only $4.0 \%$ were antibiotics (35).

Tablets were the formulations most commonly used for self-medication (35.6\%). However, it should be emphasized that tablets might be the most frequently used dosage form in self-medication simply because most medicines for self-medication come in tablet form.

It is not surprising that nearly $10 \%$ of households kept herbal remedies. Selfmedication with herbal preparations is likely to be frequent in south-east Islamic Republic of Iran because people in 
this area are proud of their background related to traditional medicine. Previous studies in the Islamic Republic of Iran show that people take herbs as supplements to promote health, prevent illness (especially the common cold), boost the immune system, prevent stress and to supplement regular nutrition and they believe that use of herbs is part of a healthy lifestyle $(36,37)$.

One of the strengths of the present study was that it was carried out in the community and was not based on a specific target group. However, an absence of a standard definition of selfmedication and the study design which did not include a comparison group mean the results should be interpreted with caution.

\section{Conclusions}

Keeping medicines at home and selfmedication are important health issues. Very few householders in our study consulted the package inserts or stored their medicines according to the manufacturers' instructions. It is important for patients to be aware of information about manufacturers' recommended storage conditions for medicines. There is a need for more patient awareness about the safe handling and storage of medicines at home. A high prevalence of self-medication was also noted among householders, especially those who were less welleducated. Doctors have to take into account that their patients are likely to keep several prescription medicines in their homes. These patients are potential providers to their friends and relatives of medicines that are potentially unsafe for self-medication. Better public knowledge and information about the risks of reuse of prescription medications is needed.

\section{Acknowledgements}

The authors would like to express their gratitude towards all the respondents for showing concern towards this issue and also to thank Mr Javadinia for his contribution to data collection.

\section{Funding: None.}

Competing interests: None declared.

\section{References}

1. Stosic R, Dunagan F, Palmer H, Fowler T, Adams I. Responsible self-medication: perceived risks and benefits of over-thecounter analgesic use. Int J Pharm Pract. 2011 Aug;19(4):23645. PMID:21733011

2. Hughes $\mathrm{CM}, \mathrm{McElnay} J \mathrm{C}$, Fleming GF. Benefits and risks of self medication. Drug Saf. 2001;24(14):1027-37. PMID:11735659

3. Hayran O, Karavus M, Aksayan S. Help-seeking behavior and self-medication of a population in an urban area in Turkey: cross sectional study. Croat Med J. 2000 Sep;41(3):327-32. PMID:10962055

4. Beitz R, Dören M, Knopf H, Melchert HU. Selbstmedikation mit Over-the-Counter-(OTC-)Praparaten in Deutschland. [Self-medication with over-the-counter (OTC) preparations in Germany]. Bundesgesundheitsblatt Gesundheitsforschung Gesundheitsschutz. 2004 Nov;47(11):1043-50. PMID:15549197

5. Grigoryan L, Monnet DL, Haaijer-Ruskamp FM, Bonten MJ, Lundborg S, Verheij TJ. Self-medication with antibiotics in Europe: a case for action. Curr Drug Saf. 2010 Oct;5(4):329-32. PMID:20615180

6. Grigoryan L, Burgerhof JG, Degener JE, Deschepper R, Lundborg CS, Monnet DL, et al.; Self-Medication with Antibiotics and Resistance (SAR) Consortium. Determinants of self-medication with antibiotics in Europe: the impact of beliefs, country wealth and the healthcare system. J Antimicrob Chemother. 2008 May;61(5):1172-9. PMID:18296694

7. Sandler G. South Africa: self-medication. Lancet. 1990 May 12;335(8698):1149. PMID:1971877

8. Aoyama I, Koyama S, Hibino H. Self-medication behaviors among Japanese consumers: sex, age, and SES differences and caregivers' attitudes toward their children's health management. Asia Pac Fam Med. 2012;11(1):7. PMID:22962853

9. Pan H, Cui B, Zhang D, Farrar J, Law F, Ba-Thein W. Prior knowledge, older age, and higher allowance are risk factors for self-medication with antibiotics among university students in southern China. PLoS One. 2012;7(7):e41314. PMID:22911779
10. Al-Ramahi R. Patterns and attitudes of self-medication practices and possible role of community pharmacists in Palestine. Int J Clin Pharmacol Ther. 2013 Jul;51(7):562-7. PMID:23587151

11. Sahebi L, Vahidi RG. Self-medication and storage of drugs at home among the clients of drugstores in Tabriz. Curr Drug Saf. 2009 May;4(2):107-12. PMID:19442102

12. Sedighi B, Ghaderi-Sohi S, Emami S. Evaluation of self-medication prevalence, diagnosis and prescription in migraine in Kerman, Iran. Neurosciences (Riyadh). 2006 Apr;11(2):84-7. PMID:22266554

13. Awad AI, Eltayeb IB. Self-medication practices with antibiotics and antimalarials among Sudanese undergraduate university students. Ann Pharmacother. 2007 Jul;41(7):1249-55. PMID:17565044

14. Montastruc JL, Bagheri H, Geraud T, Lapeyre-Mestre M. Pharmacovigilance de l'automedication. [Pharmacovigilance of self-medication]. Therapie. 1997 Mar-Apr;52(2):105-10. PMID:9231503

15. Public education in rational drug use : report of an informal consultation, Geneva, 23-26 November 1993. Geneva: World Health Organization; 1993. pp. 23-6.

16. Statistical abstract of the United States 2004-05 at 93 tbl.116 (124th ed. 2005). Washington (DC): US Census Bureau; 2005.

17. Cameron KA. Comment on medication management models and other pharmacist interventions: implications for policy and practice. Home Health Care Serv Q. 2005;24(1-2):73-85. PMID:16236660

18. Barah F, Gonçalves V. Antibiotic use and knowledge in the community in Kalamoon, Syrian Arab Republic: a crosssectional study. East Mediterr Health J. 2010 May;16(5):516-21. PMID:20799551

19. Sclafer J, Slamet LS, de Visscher G. Appropriateness of self-medication: method development and testing in urban Indonesia. J Clin Pharm Ther. 1997 Aug;22(4):261-72. PMID:9548207 
20. Kheir N, Hajj ME, Wilbur K, Kaissi R, Yousif A. An exploratory study on medications in Qatar homes. Drug Healthc Patient Saf. 2011;3:99-106. PMID:22279414

21. Jassim AM. In-home Drug Storage and Self-medication with Antimicrobial Drugs in Basrah, Iraq. Oman Med J. 2010 Apr;25(2):79-87. PMID:22125705

22. Muras M, Krajewski J, Nocun M, Godycki-Cwirko M. A survey of patient behaviours and beliefs regarding antibiotic selfmedication for respiratory tract infections in Poland. Arch Med Sci. 2013 Oct 31;9(5):854-7.

23. Poirier S, Barbeau G. An in-home medication inventory among elderly receiving home care services. J Geriatr Drug Ther. 1999;12(3):43-54.

24. Thompson S, Stewart K. Prescription medication use practices among non-institutionalised older persons. Int J Pharm Pract. 2001;9(3):141-51

25. Habibzadeh A, Alizadeh M, Malek A, Maghbooli L, Shoja MM, Ghabili K. Illicit methylphenidate use among Iranian medical students: prevalence and knowledge. Drug Des Devel Ther. 2011;5:71-6. PMID:21340040

26. Amidi S, Ajamee G, Sadeghi HR, Yourshalmi P, Gharehjeh AM. Dispensing drugs without prescription and treating patients by pharmacy attendants in Shiraz, Iran. Am J Public Health. 1978 May;68(5):495-7. PMID:646001

27. Bijani A, Hasanjani Roshan AR, Yazdanpour S, Hosseini SR. Are older women likely to use medicines than older men? Results from AHAP study. Caspian J Intern Med. 2014 Spring;5(2):77-81. PMID:24778781

28. Zargarzadeh AH, Tavakoli N, Hassanzadeh A. A survey on the extent of medication storage and wastage in urban Iranian households. Clin Ther. 2005 Jun;27(6):970-8. PMID:16117997
29. Asefzadeh S, Nassiri-asl M. Drugs at home in Qazvin, Iran: community based participatory research. Eur J Sci Res. 2009;32(1):42-6.

30. Yousef AM, Al-Bakri AG, Bustanji Y, Wazaify M. Self-medication patterns in Amman, Jordan. Pharm World Sci. 2008 Jan;30(1):24-30. PMID:17562220

31. Nunes de Melo M, Madureira B, Nunes Ferreira AP, Mendes Z, Miranda Ada C, Martins AP. Prevalence of self-medication in rural areas of Portugal. Pharm World Sci. 2006 Feb;28(1):19-25. PMID:16703269

32. Dineshkumar B, Raghuram TC, Radhaiah G, Krishnaswamy K. Profile of drug use in urban and rural India. Pharmacoeconomics. 1995 Apr;7(4):332-46. PMID:10155322

33. Sepehri G, Khazaelli P, Dahooie FA, Sepehri E, Dehghani MR. Prevalence of potential drug interactions in an Iranian general hospital. Indian J Pharm Sci. 2012 Jan;74(1):75-9. PMID:23204627

34. Abou-Auda HS. An economic assessment of the extent of medication use and wastage among families in Saudi Arabia and Arabian Gulf countries. Clin Ther. 2003 Apr;25(4):1276-92. PMID:12809973

35. Daniszewsi, R., et al., An investigation of medicines returned to general practitioners and community pharmacies. Int J Pharm Pract. 2002;10 Suppl:R42.

36. Hasani-Ranjbar S, Nayebi N, Larijani B, Abdollahi M. A systematic review of the efficacy and safety of herbal medicines used in the treatment of obesity. World J Gastroenterol. 2009 Jul 7;15(25):3073-85. PMID:19575486

37. Hasani-Ranjbar S, Larijani B, Abdollahi M. A systematic review of the potential herbal sources of future drugs effective in oxidant-related diseases. Inflamm Allergy Drug Targets. 2009 Mar;8(1):2-10. PMID:19275687 